\title{
Capítulo ViII \\ LA CÁTEDRA DE ÉTICA EN LA USTA Y SU IMPORTANCIA EN LA FORMACIÓN DE LOS ESTUDIANTES
}

Roberto Dáger ${ }^{1}$

\section{Introducción}

La enseñanza de la ética en los momentos actuales del país tiene unas características problemáticas debido a algunos fenómenos sociales y políticos que interrogan el sentido de la misma. En efecto, se cuestiona por diversos sectores de la sociedad y del estado, la misión de la universidad colombiana en la formación del futuro profesional colombiano, en aspectos de su perfil: su idoneidad profesional, sus competencias ciudadanas y su compromiso para ser parte de la solución de los grandes problemas que afronta la sociedad colombiana.

En tal sentido, a la universidad colombiana se le exige su aporte a la solución de flagelos como la inequidad social, la corrupción tanto pública como privada, la violencia en todas sus

1 Licenciado en Filosofía y Letras de la Universidad Santo Tomás, con especialización en Resolución de Conflictos de la Pontificia Universidad Javeriana y en Docencia Universitaria de la Universidad Santo Tomás. Magíster en Estudios Políticos de la Pontificia Universidad Javeriana. 
manifestaciones, la violación sistemática de los Derechos Humanos, entre otros aspectos. Este requerimiento a la universidad se fundamenta en varias razones: por cuanto se reclama que ella debe contribuir a la solución de los grandes problemas del país. En tal sentido, la universidad no puede conformarse con graduar profesionales exitosos en una sociedad fracasada. Es preciso recordar, además, que en ella se forma el futuro profesional que ejercerá sus conocimientos en todos los sectores: tanto público como privado y probablemente tomará decisiones que afectarán a toda una comunidad o al Estado ${ }^{2}$. Se exige entonces que tanto los estudiantes universitarios como la academia, comprendan su responsabilidad histórica en la solución de dicha problemática y se formen en un sentido integral, no solo por ser una exigencia legal, sino también por ser parte de la esencia de toda universidad.

Desde ese punto de vista la formación ética en las universidades debe tener presente que desde la antigüedad se viene discutiendo sobre la misión que cumple la educación para el desarrollo del ser humano y de la relación de ella con la sociedad. Es preciso recordar que el poeta griego Píndaro estableció la tarea ética de todo ser humano al expresar en un poema la frase "Hazte como el que eres", significando con ello que es deber de toda persona encontrar su propia voz moral que proporcione la identidad entre el ser y el hacer. Esta tarea se torna en una búsqueda y un proyecto a la vez, en la medida en que, gracias a la capacidad de reflexión del ser humano, es capaz de vivir una vida proba, basada en normas morales que dignifican su vida y lo acercan a la felicidad, al bienestar o, en términos aristotélicos, a la vida virtuosa.

Hoy en día tenemos que reconocer que desde que el ser humano desarrolló su conciencia, empezó paralelamente a plantearse los interrogantes éticos sobre si es correcto o justo actuar de una determinada manera o en la situación de tener que juzgar la conducta de los otros. Al respecto, el poeta John Donne expresaba que "ningún hombre es una isla, algo completo en sí mismo; todo hombre es un fragmento del continente, una parte de un conjunto"3.

En efecto, la ética obliga a plantear la dimensión relacional del ser humano, es decir, el aspecto de convivir con otros, de su apertura, que por lo tanto trasciende su mundo interno. En tal sentido, la ética tiene un fuerte componente social, en la medida en que ella explica una relación entre un ser humano con los otros, las instituciones o la naturaleza. Por tal razón, cuando alguien decide sobre varias opciones o actúa basándose en aspectos, como su interés personal o en principios altruistas o solidarios, hace unas elecciones que desde la ética se pueden interpretar.

2 Roberto Dáger, Ética y universidad, ponencia presentada en la Universidad La Gran Colombia, (2013).

3 John Donne, Devociones. (Buenos Aires: Editorial Brújula, 1969). 
Una pregunta necesaria y recurrente es la finalidad de la ética; desde la antigüedad han surgido diversas respuestas, lo que posibilita comprender que la ética no es unívoca, pero tampoco relativa. Una de las posiciones interesantes es la del filósofo griego Sócrates, para quien hay que diferenciar entre la buena vida y la vida buena. La primera puede entenderse desde un hedonismo que pretende la consecución del placer y la segunda exige vivir una vida virtuosa, guiada por el logos (razón).

Recordemos que Sócrates fue acusado, juzgado y condenado por corromper la juventud, y de impiedad, por tratar de introducir otros dioses a Atenas; el veredicto es implacable: debe beber la cicuta. Sus discípulos y amigos, ante lo que consideran una injusticia del jurado en la democracia de Pericles, le plantean a Sócrates la posibilidad de escapar, pues todo está arreglado para la huida. Incluso, le dejan entrever que el pueblo que lo juzgó y condenó, comprendería el hecho de la fuga.

Sócrates le argumenta a Critón que él solo "cede ante razones justas después de haberlas examinado detenidamente", pues, "aunque la fortuna le sea adversa, no puede abandonar las máximas de que siempre ha hecho profesión; ellas le parecen siempre las mismas y, como las mismas, las estima igualmente".

Es importante resaltar el tema de fondo planteado en este diálogo, toda vez que él estará presente en los debates éticos a lo largo de la historia; basta recordar al respecto dos aspectos que refuerzan lo anterior. Por una parte, la tesis en la edad moderna de Thomas Hobbes, quien sostendrá que al hombre lo inspira más en el amor propio que el deber moral; es decir, que si hay que escoger entre el interés particular y el deber moral hacia los otros, probablemente nos inclinamos más por lo primero. Es la expresión de la teoría del egoísmo, tan debatida en la historia de la ética.

Actualmente el sociólogo Amitai Etzioni plantea varias "resistencias" que se generan en la formación ética en instituciones de educación superior ${ }^{5}$ : Resistencia por parte de los profesores que prefieren "enseñar ciencia" y no cualquier asignatura de "humanidades", por cuanto consideran que es perder el tiempo en la educación del estudiante. Con cierto sarcasmo esos docentes sostienen que la ética se torna relativa por cuanto pertenece a la doxa (la opinión) y no a ninguna disciplina. Ellos se preguntan: “¿qué ética vamos a enseñar? ¿La ética de quién? y ¿por qué esta y no otra?, ¿qué utilidad tendrá para la formación profesional del estudiante?” etc.

4 Platón, Diálogos, Critón o del deber, estudio preliminar de Francisco Larroyo (México: Porrúa, 1998).

5 Amitai Etzioni, When It Comes to Ethics, B-Schools Get an F (Washington :The Washington Post, 2002), http://www.washingtonpost.com/archive/opinions/2002/08/04/when-it-comes-to-ethics-bschools-get-an-f/c92d6899-fd20-4451-8ca1-113708f5ef92/ 
Así mismo, por parte de los estudiantes se da un primer tipo de resistencia cuando perciben el curso de ética como una pérdida de tiempo, un "relleno" o de todos modos algo que no tiene que ver con su formación profesional, sino más bien como un adoctrinamiento: "es como ir a la Iglesia los domingos" ${ }^{6}$. Un segundo tipo de resistencia por parte de los estudiantes, que entienden la preocupación ética en los negocios como un obstáculo en su competitividad, toda vez que quien sigue los preceptos éticos está en desventaja frente a los competidores. Prevalece entonces la racionalidad económica, la utilidad y ganancias a través del cálculo racional.

Todo lo anterior conlleva a la "des-enseñanza ética”, como señala Etzioni: "la educación en estas instituciones no solo falla en mejorar los valores morales de los estudiantes, sino que los deteriora" 7 .

\section{La cátedra de ética en la Universidad Santo Tomás}

Recordemos que la ética es una dimensión humana y por lo tanto, es necesario responder a la pregunta sobre la fundamentación humana de ella. En primer lugar, se exige plantearse el interrogante del por qué somos éticos. A primera vista, se podría afirmar que el ser humano pretende en últimas ser feliz, buscar el bienestar o realizar el bien que en cualquier circunstancia le dará sentido a su vida. Existe entonces esa tendencia humana a hacer el bien, ser solidario o ser justos y evitar todo lo contrario. Cuando ocurre lo segundo en desmedro de lo primero, la conciencia se enfrenta a esas situaciones y se produce lo que se conoce como una disonancia moral, en la medida que se presenta una especie de desequilibrio.

En segundo lugar, se podría afirmar que existe también la tendencia humana a superarnos a nosotros mismos, lo que significa que cada día pretendemos ser mejores o, en términos de la ética aristotélica, ser virtuosos. Lo anterior se puede entender, además, como la pretensión por superar las limitaciones, condicionamientos y obstáculos para realizar la vida buena.

Dicho la anterior, debemos reconocer que la dimensión ética irradia el quehacer de la Universidad en todas sus funciones desde el PEI, que establece en su misión la promoción de una formación integral en las personas para responder "de una manera ética, creativa y crítica a las exigencias de la vida humana", en el marco de una concepción humanista que se caracteriza por
6 Ibíd.
7 Ibíd. 
"la sustentación del valor del hombre y por su optimismo sobre las posibilidades de la realización

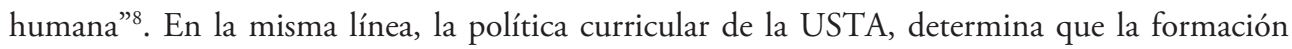
integral se articula con aspectos personales y profesionales desde una madurez ética. Por ello, "los valores de desarrollo personal y los de convivencia, no funcionan de manera aislada, sino en plexo, es decir, como red de elementos entrelazados" $"$.

El proyecto de ética constituye un aporte directo a la consecución de una humanidad constructora y dichosa del bien común ${ }^{10}$. Se parte de una máxima cristiana fundamental y es que la paz no se alcanza con el fin de la guerra, sino a través de una distribución equitativa de oportunidades. La búsqueda del bien común pretende superar las falsas concepciones de vida, sobre todo provenientes del proyecto moderno y del capitalismo neoliberal, que colocan al hombre en un escenario de extrema individualidad donde el progreso personal no da lugar a experiencia de solidaridad y la competencia económica es sinónimo de libertad. Los discursos y prácticas dentro del presente proyecto pretenden llevar al estudiante por un proceso de reflexión crítico frente a los estereotipos de vida que se venden a través de los medios y que se aceptan como únicos y verdaderos para que aprenda a juzgarlos como mecanismos sociales que degradan la vida humana en tanto productores de egoísmo, placer individual y mezquindad ${ }^{11}$.

El espacio académico de ética se perfila como el culmen de la formación humanística por la que ha apostado la Universidad Santo Tomás. Tras un largo itinerario por diferentes procesos formativos en que fueron puestas en escena diversas problematizaciones relativas al estudio de los contextos, de la institucionalidad (Filosofía Institucional), a la pregunta por nosotros mismos en tanto personas social, histórica y culturalmente situadas (antropología) y en perspectiva de nuestras relaciones con los otros (política), con los procesos de conocimiento (epistemología) y con lo Absolutamente Otro (cultura teológica), conviene nuevamente ubicarnos en el centro de la reflexión para pensar-nos en perspectiva de nuestra condición ético-política y como sujetos de acción y producción moral (Ética).

8 Universidad Santo Tomás. Proyecto Educativo Institucional PEI (Bogotá: Universidad Santo Tomás, USTA, 2004).

9 Universidad Santo Tomás, Política curricular para programas académicos (Bogotá: Universidad Santo Tomás, 2004).

10 François Vellaeys, Orientaciones para la enseñanza de la ética, el capital social y el desarrollo en las universidades latinoamericanas, Revista Venezolana de Gerencia Vol. 8 N 21 (2003), 38-73.

11 Departamento de Humanidades y Formación Integral, Proyecto de Cátedra de Ética (Bogotá: Universidad Santo Tomás, 2015). 
Desde ese punto de vista, la cátedra de ética responde a un proyecto pedagógico de la universidad, en la medida que posibilita la formación integral de sus estudiantes. Se comprende para ello que "la formación es un proceso permanente de construcción donde todo proyecto educativo-pedagógico estaría orientado a la realización plena del hombre como fin, como sujeto de su deber ser y poder ser, con autonomía"12.

En este contexto, el curso de ética propende por dar continuidad al abordaje de procesos de reflexión crítica respecto de nuestra obligante y obligatoria dimensión moral; por ello, se proponen algunos ejes problematizadores que buscan dar cuenta de unos fundamentos teóricos y prácticos en los que se juega y se pone en escena la propia existencia. La cátedra es un espacio en el que cada estudiante vive y fundamenta su ética personal, la proyecta en la ética social y, finalmente, la asume de manera responsable, con sus demás congéneres en el ámbito de la ética global. La responsabilidad por nuestro futuro y el de los demás implica que cada uno sienta principios y valores humanísticos, principios de valoración y cuidado, tanto de la vida como de lo que existe en el planeta.

La reflexión acerca de la ética, la moral, la axiología y la deontología ha cobrado en nuestro tiempo especial relieve y significado como una alternativa eficaz frente a los altos índices de corrupción y a los hechos generadores de la degradación humana. La situación por la que atraviesa la humanidad parece haber lanzado al hombre hacia horizontes sin dirección, abocado a su libertad, responsabilidad y autonomía, pero sin mayores recursos que permitan que la sociedad misma reoriente su itinerario. Es aquí donde se ha de asumir la reflexión sobre el obrar humano, sus circunstancias y complejidad. Reflexión alternativa que frente al vivir la vida se plantea la pregunta de cómo vivirla; frente a la necesidad y a la posibilidad de vivir una buena vida, de darse la buena vida, se plantea la urgencia de vivir una vida más humana, más digna y feliz. Una reflexión comprometida y responsable que coadyuve a que el hombre (estudiante tomasino) visualice el rumbo de su existencia y se proyecte en ella, y a través de la historia, como el único ser capaz de poseerse a sí mismo y construir su proyecto de vida bajo circunstancias constructivas de una verdadera actividad moral liberadora.

Hoy es común escuchar que vivimos en crisis en distintas dimensiones: económica, ecológica, política, profesional e incluso familiar. Algunos autores han expresado que la solución es volver a la ética no como un conocimiento "accidental-circunstancial-acomodaticio" algo

12 Vicerrectoría Académica, Modelo Educativo Pedagógico (Bogotá: Universidad Santo Tomás, 2009), 10. 
externo al ser humano, sino más bien como un saber fundamental-sustancial y constitutivo de la vida humana.

La cátedra de ética asumirá, por tanto, que la reflexión sobre la moral se fundamentará en que no existe escisión o división entre la vida y la ética, que ellas no recorren caminos diferentes, sino por el contrario, deben formar una unidad indisoluble, toda vez que la ética es en últimas, saber vivir bien; es vivir de conformidad con el proyecto de vida que incorpora las distintas dimensiones humanas: lo antropológico, lo biológico, lo cognitivo, lo político y lo económico.

\section{Propósitos del espacio académico}

La Universidad Santo Tomás, heredera de la tradición dominicana y tomasina, propende por la formación integral de las personas, desde los procesos de enseñanza- aprendizaje, investigación y proyección social en aras de la formación de profesionales que respondan de manera ética, creativa y crítica a las exigencias de la vida humana y estén en condiciones de aportar a las necesidades de la sociedad y el país ${ }^{13}$. La Universidad busca cumplir con estos objetivos a través de la articulación de la formación científica con la formación humanística, modelo de formación integral del profesional, el ciudadano y el cristiano.

La cátedra de ética propende por dar continuidad al abordaje de procesos de reflexión crítica respecto de nuestra obligante y obligatoria dimensión moral; por ello, se proponen algunos ejes problematizadores que buscan dar cuenta de unos fundamentos teóricos y prácticos en los que se juega y se pone en escena la propia existencia. La cátedra es un espacio en el que cada estudiante vive y fundamenta su ética personal, la proyecta en la ética social y, finalmente, la asume de manera responsable, con sus demás congéneres en el ámbito de la ética global. La responsabilidad por nuestro futuro y el de los demás implica que cada uno sienta principios y valores humanísticos, principios de valoración y cuidado, tanto de la vida como de lo que existe en el planeta.

Posibilitar la formación integral del estudiante, abriendo espacios de reflexión acerca de la moral, los valores individuales y sociales, la responsabilidad, los derechos y obligaciones a fin de hacer concreta la ética como estilo de vida tanto en el ámbito personal como profesional.

13 Universidad Santo Tomás, Consejo de fundadores. Estatuto orgánico (Bogotá: Universidad Santo Tomás, 2010). 
Proporcionar elementos de juicio, desde una perspectiva vivencial que posibilite la valoración de la acción moral en la realidad colombiana y latinoamericana, de manera que el estudiante pueda proponer o adelantar procesos de investigación, sensibilización o intervención, acordes al portafolio de problemas y grupos de interés.

\section{Metodología}

El Departamento de Humanidades y Formación Integral se caracteriza por la formación humanista. De tal modo que la cátedra de ética presupone un contenido mínimo previo de los principales conceptos antropológicos, culturales, tomísticos y teológicos. Es decir, es importante para la cátedra que el proceso de promotio del estudiante corresponda a la formación humanística e integral con la que está comprometida la Universidad en su perspectiva misional institucional.

A partir del Modelo Pedagógico de la Universidad, se comprende la relación docenteestudiantes como una relación dialógica en la que ambos son actores del proceso pedagógico y cuyo propósito principal está centrado en desarrollar habilidades y promover así el discernimiento humanístico.

Con este plan se busca evitar el aprendizaje mecánico y memorístico. En este sentido, las clases tienen momentos de presencialidad con acompañamiento del docente y trabajo autónomo, a partir de actividades extraclase que realiza el estudiante, ya sea en trabajo, en equipo o autónomo.

La metodología se desarrolla a través varios momentos: planteamiento del problema, búsqueda de alternativas de solución, discusión y profundización.

Por su parte, el docente asume la orientación de la problemática, la discusión y profundización del tema. En cuanto al estudiante, él se hace responsable de la consulta e investigación bibliográfica o de campo y de la aplicación o producción de nuevo material (textos, gráficos, videos, entre otros), tal como se expresa a lo largo del Modelo Educativo Pedagógico. ${ }^{14}$

Lo anterior se logra a través de exposiciones del profesor y los estudiantes, controles de lectura, conferencias, salidas pedagógicas, foros, talleres y otras actividades creativas que el profesor proponga y/o los alumnos sugieran.

14 Vicerrectoría Académica, Modelo Educativo Pedagógico (Bogotá: Universidad Santo Tomás, 2009). 
La pedagogía problémica no trabaja con competencias, sino favoreciendo el desarrollo de las actitudes de la persona humana, tales como el comprender, hacer, obrar y comunicar.

\section{Tabla 1}

\begin{tabular}{|c|c|c|}
\hline Comprender & $\begin{array}{l}\text { Visión racional } \\
\text { estructural de la } \\
\text { realidad }\end{array}$ & $\begin{array}{l}\text { Análisis, interpretación, síntesis y argumen- } \\
\text { tación del conocimiento, de los principios, } \\
\text { conceptos, teorías, lenguajes y métodos, y de la } \\
\text { capacidad de recontextualización de los núcleos } \\
\text { problémicos de acuerdo a los propósitos de } \\
\text { formación institucional y profesional }\end{array}$ \\
\hline Hacer & $\begin{array}{c}\text { Acción } \\
\text { transformadora y } \\
\text { productora }\end{array}$ & $\begin{array}{l}\text { De las habilidades y destrezas propias de la cáte- } \\
\text { dra, manejo de tecnologías e instrumentos para } \\
\text { el desarrollo de la asignatura, habilidades para } \\
\text { formular y evaluar proyectos. }\end{array}$ \\
\hline Obrar & $\begin{array}{c}\text { Acción conforme a } \\
\text { valores éticos }\end{array}$ & $\begin{array}{l}\text { Respeto y solidaridad, sentido crítico-propositi- } \\
\text { vo y resignificación de aprendizajes desarrollados } \\
\text { a partir de la interacción con el otro, apertura } \\
\text { y reconocimiento del otro como interlocutor } \\
\text { válido y desarrollo de la sensibilidad y la respon- } \\
\text { sabilidad social. }\end{array}$ \\
\hline Comunicar & $\begin{array}{c}\text { Interacción a } \\
\text { través de diferentes } \\
\text { lenguajes }\end{array}$ & $\begin{array}{l}\text { Escucha, expresión verbal clara, expresión } \\
\text { escrita, capacidad para expresar las inquietudes } \\
\text { propias, dominio de lenguajes específicos de las } \\
\text { cátedras, capacidad para presentar proyectos, } \\
\text { uso de los lenguajes multimedia, manejo de } \\
\text { recursos simbólicos y capacidad para el trabajo } \\
\text { en equipo. }\end{array}$ \\
\hline
\end{tabular}

Fuente: tabla construida a partir de Política curricular para programas académicos. Universidad Santo Tomás. $2004{ }^{15}$

Favorecer la escucha, expresión verbal clara, expresión escrita, capacidad para expresar las inquietudes propias, dominio del lenguaje específico de la cátedra, capacidad para presentar

15 Política curricular para programas académicos, Op. Cit. 
proyectos, uso de los lenguajes multimedia, manejo de recursos simbólicos y capacidad para el trabajo en equipo.

\section{Conclusiones}

La enseñanza de la ética en las universidades se torna desafiante dadas las circunstancias que caracterizan nuestra realidad; el sentido y la finalidad de dicha enseñanza son interrogantes que marcan el quehacer de la academia. Es innegable que en torno a dicha enseñanza se ciernen algunas resistencias por parte de sectores endógenos (docentes, estudiantes, directivos) a las universidades, como también exógenos (empresarios, funcionarios públicos, medios de comunicación). Esa repulsión obedece a aspectos utilitaristas que preguntan por la utilidad de enseñar ética en un mundo donde debe imperar el lucro y la ganancia; también a aspectos epistemológicos en tanto consideran que la ética pertenece al mundo de la opinión (doxa) y por lo tanto se vuelve relativa, pues todas las opiniones valen, lo que significaría que no habría comportamientos correctos o incorrectos, justos o injustos, ni valores absolutos o universales.

No obstante, este reto a las universidades se debe tomar como una posibilidad para crear las posibilidades a través de la enseñanza de la ética que permita reflexionar sobre el razonamiento moral en torno a valores propios, y no sobre razonamientos de estándares abstractos de la conducta de los otros. No se entienda por ello la pretensión de una rampante casuística sin fundamentos teóricos de la ética.

Tampoco las universidades pueden caer en la trampa de un "utopismo pedagógico" entendido como la exigencia que se le realiza a ella para que resuelva problemas como la violencia, la corrupción, el deterioro del medio ambiente o la violación de los Derechos Humanos en una sociedad determinada. A la universidad no se le puede exigir que solucione lo que la sociedad y el estado se niegan a corregir.

La universidad sí puede contribuir, a través de la formación integral que brinda a sus estudiantes por preparar a sus futuros egresados, para que tomen las decisiones justas en aras del beneficio colectivo y en la construcción de referentes públicos indispensables para la solución de los flagelos que nos agobian como sociedad y como nación.

Lo anterior debe complementarse con el compromiso de que los demás sectores sociales y gubernamentales también incluyan la ética como referente en sus actuaciones y no practiquen una especie de lógica perversa: hacer todo lo contrario de lo que le exigen a las universidades en la formación de los futuros profesionales. 
Este reto lo ha asumido la Universidad Santo Tomás desde la formación integral que brinda a través del Departamento de Humanidades y Formación Integral en forma coordinada con las demás dependencias académicas y administrativas, por cuanto no tendría sentido que lo haga dicho Departamento en forma exclusiva y excluyente.

Finalmente, cuando se trata de formación integral (corporal, cognitiva, política, ética, etc), debe realizarse por todos los actores que en ella intervienen: académicos, políticos, administrativos y sociales y cabe tanto para el interior de los centros de educación superior como para los estamentos estatales y sociales.

Una causa común en defensa de valores compartidos: la construcción de lo público y de un orden justo y equitativo, el respeto y garantía por los derechos humanos, la protección del medio ambiente y, por supuesto, el respeto por la dignidad humana: una tarea pendiente e inaplazable para el país.

\section{Referencias}

Dáger, Roberto. Ética y universidad. Ponencia presentada en la Universidad La Gran Colombia. (2013).

Departamento de Humanidades y Formación Integral. Proyecto de cátedra de ética. Bogotá: Universidad Santo Tomás, 2015.

Donne, John. Devociones. Buenos Aires: Editorial Brújula, 1969.

Etzioni, Amitai. When It Comes to Ethics, B-Schools Get an F. (Washington: The Washington Post, 2002). http://www.washingtonpost.com/archive/opinions/2002/08/04/when-it-comes-to-ethics-b-schoolsget-an-f/c92d6899-fd20-4451-8ca1-113708f5ef92/

Platón. Diálogos. Crítón o del deber, estudio preliminar de Francisco Larroyo. México: Porrúa, 1998.

Universidad Santo Tomás. Proyecto Educativo Institucional PEI. Bogotá: Universidad Santo Tomás, USTA, 2004.

Universidad Santo Tomás. Politica curricular para programas académicos. Bogotá: Universidad Santo Tomás, 2004.

Universidad Santo Tomás. Consejo de fundadores Estatuto orgánico, Bogotá: Universidad Santo Tomás, 2010.

Vellaeys, François. Orientaciones para la enseñanza de la ética, el capital social y el desarrollo en las universidades latinoamericanas. Revista Venezolana de Gerencia Vol. 8 Nº 21 (2003):38-73.

Vicerrectoría Académica. Modelo Educativo Pedagógico. Bogotá: Universidad Santo Tomás, 2009. 
